\title{
Tacit Knowledge Management and Its Philosophical Analysis
}

\author{
Huachu Liu ${ }^{1, \text { a }}$ \\ ${ }^{1}$ Dept. Of Social Science, Hainan Normal University, \\ Haikou, Hainan province, China, 571158 \\ a liuhuachu88@163.com
}

\begin{abstract}
With the advent of knowledge economic age, features of tacit knowledge and its production are not only issues of economics but also ones for philosophers. The transforms between explicit knowledge and tacit knowledge, between knowledge and social construction contains philosophical values and possibility of connecting multi-disciplines. By philosophical analysis, This paper represents the hierarchy of knowledge and social features of knowledge management $(\mathrm{KM})$ and reveals that tacit knowledge is a kind of action-inherent knowledge or actionconstructive knowledge, so it contains a lot of active elements' participation in the acquisition and transfer process of knowledge; "learn by doing" is related to tacit knowledge, management science of $\mathrm{KM}$ and cognitive science is connected; in the dimension of sociology, SECI model is investigated in details by a new approach of social ecology of KM.
\end{abstract}

Keywords- tacit knowledge; knowledge management; SECI; philosophical analysis; epistemology

\section{INTRODUCTION}

Knowledge used to be a symbol of intelligence of the mankind. Knowledge is virtue for Socrates but power for Bacon. According to Peter Drucker, the significance of knowledge has changed three times during the past century. At first time it was applied in industrial production, secondly it was applied in our activities, and finally it was used primarily for production of itself. The meaning and value of knowledge has been changing continuously with time going on, and also from one society to another. The changing tendency leads to the economic policy arguments that claim to be grounded upon well-established propositions about scientific technologies' stimulus function to the economics, since scientific techniques are typical knowledge with high commercial value. Indeed, with the arrival of knowledge economy age, knowledge is widely utilized to generate various kinds of tangible and intangible economic values. Actually knowledge has become a most important capital, particularly in most developed countries. Some optimistic estimation suggests the percentage of knowledge's contribution to economic would grow from $10 \%$ or so in early 20 century up to $80 \%$ in some time of the 21 century. Drucker highly emphasize the significance of knowledge by saying that knowledge is the sole meaningful resource in new economic systems, because it is the resource itself rather than one type. ${ }^{[1]}$

In order to make clear knowledge's features, philosophers differentiate knowledge into different categories by the way of its acquaintance, description, transfer and so on. Aristotle classified knowledge in three types: episteme (scientific knowledge), techne (skill and crafts) and phronesis (practical wisdom). His terminology implies the explicit and implicit distinction, since episteme means "to know" explicit knowledge in Greek, while the latter two are not easy to share each other. In modern philosophy, the theory about knowledge is a kind of product of doubt. If we seriously ask such a question as whether we really know anything at all, we would have to distinguish trustworthy beliefs from untrustworthy ones. As the founder of modern theory of knowledge, Kant represents a natural reaction against Hume's skepticism and defense scienfitic knowledge. However thinkers after Kant and Hegel are inclined to relate knowledge to will, life and individual experiences. B. Russell divides knowledge according to experience's types of direct, indirect and implicit. Because of the importance of knowledge in modern economic activities, OECD distinguishes knowledge into four major types: know-what, know-why, know-how, and know-who.

The conception of tacit knowledge was first introduced into modern circulation by Michael Polanyi in 1958 in his magnum opus Personal Knowledge. By the words "we can know more than we can tell" ${ }^{[2]}$, he suggests that there is a tacit dimension of knowledge. It is not a formal sort of knowledge, i.e. not a codified knowledge but complementary to human knowledge that is explicit in our cognitive processes. The existence of such a kind of knowledge renders that all kinds of knowledge cannot be adequately articulated by verbal proposition, and moreover, all kinds of knowledge are rooted in tacit knowledge in the strong sense of the term. That sounds like what Freud said about sub-consciousness. Similarly, we are neither usually aware the existence of tacit knowledge nor its value, let alone its effective transfer in our extensive personal contact, various daily activities, social communication and cultural surroundings in the social networks such as driving a car, riding a bike and playing the piano.

Since Polanyi put forward the theory of tacit knowledge, increasing interest has been focused on tacit knowledge, not only is the vision of epistemology widely open and its research content enriched, but also knowledge management has substantial subject-matter. According to Yogesh Malhotra, KM (Knowledge Management) caters to the critical issues of organizational adaption, survival and competence in face of increasingly discontinuous environmental change. It essentially embodies organizational processes that seek synergistic combination of data and information processing capacity of information technologies, and the creative and innovative capacity of human beings. ${ }^{[3]}$ From the viewpoint of the current entire thought tendency since the middle 20 century, the influence of postmodernism upon $\mathrm{KM}$ is not negligible. Therefore tacit knowledge appears some postmodernist features 
including the qualities of culture, context and value, which were actually expressed by Polanyi in his works.

However, tacit knowledge management is not mature yet due to its ignorance on the explicating mechanism of tacit knowledge, since the transform between explicit knowledge and tacit knowledge becomes an issue of economics rather than a philosophical issue. But in order to clarify the mechanism of the explicating and transform, we must inquiry it from all respects, particularly by philosophical analysis, since up to present, its application value and acceleration to the development of management science, methodological effects need more wide and deep inquiries. No matter how simple tacit knowledge appears to be, it has far reaching consequences and is not widely understood in methodology and philosophy. Nevertheless knowledge is not only one kind of tool or technology to produce economic benefits; instead it becomes a living style of human beings, because it creates their environment. As one kind of knowledge, tacit knowledge is not easy to transfer from one person to another by the general means such as text and verbal in comparison with explicit knowledge, while the two kinds altogether constructed the two dispensable respects of knowledge as our living environment.

\section{FEATURES AND MANAGEMENT OF TACIT KNOWLEDGE}

In the field of KM, the concept of tacit knowledge refers to a knowledge possessed only by an individual. As Polanyi suggests, tacit knowledge means what implied with out activities, what we may only be perceived but cannot be described with words. ${ }^{[4]}$ So it is usually described as "knowhow" or sometimes as "know-who" where the subject is implicitly hided in the discourse or context, as apposed to the factual knowledge which is described as "know-what", and scientific knowledge as "know-why". Since tacit knowledge generally involves operations and skills which cannot be written down or spoken out, such as an expert in a specific area makes disciplinary judgments or does complicated works and so forth without having a theory or instruction, it is difficult to communicate from one to others via words and symbols. Apprentices, for example, work with their mentors and learn craftsmanship not through language but by observation, imitation and practice. In summary, the key to acquiring tacit knowledge is experience since it is only revealed through our practice in a particular context. And it can only be transmitted through social networks, which means without some forms of shared experience it is almost impossible for different persons to share each other's thinking processes. ${ }^{[5]}$

Tacit knowledge can be distinguished from explicit knowledge in the following three major areas. At first, while explicit knowledge is easy to codify and transfer from one person to another, tacit knowledge is neither ready for codification, nor understandable due to its un-articulate and intuitive feature for different subjects. In another word, tacit knowledge is difficult to codify, describe, replicate and communicate, because it comes from human experience and senses. Experience and sense cannot be clearly articulated due to its practical feature, which is highly embodied in the interaction between our body behaviors and our living environment. The constraints of the environment to our body and activities are not all recordable to text; on the other hand, the reaction of body to the environment, for instance the operation of a worker to a machine contains a lot of personal skills and details. According to Nonaka and Takeuchi, tacit knowledge is a non-linguistic, non-numerical form of knowledge that is highly personal and context specific; so it is deeply rooted individual activities, emotions, ideas and valueviews. In Dewey's terminology, personal experience's particularity results the difficulty of learn such skills in textbook. Out of question his well-known phrase "learn by doing" is based on experiential learning.

Secondly, tacit knowledge production is different from that of explicit knowledge due to their different production processes and knowledge origins. According to Parsaye, there are three major approaches to the capture of tacit knowledge from groups and individuals: interviewing experts, learning by being told and learning by observation. By interviewing experts, the most commonly used technique for tacit knowledge, one can capture tacit knowledge in the structured process of interviewing or in the process of recording organizational stories. By listening to an expert, a novice is able to learn the processes of how to carry out a task, since there are a lot to do before the task is done, i.e. to analysis the task, to make a WBS (Work Broken Schedule) and to prepare some prerequisites for the task. By observation and emulation, a novice may learn how to face a similar problem, and how to solve the problem via case study. A case study of tacit knowledge sharing in the Australian film industry demonstrates the significance of knowledge sharing to organizational performance, and personto-person interviews elaborates the contribution of tacit knowledge sharing to the success of projects in film industry. The daily interchanges is almost entirely tacit, and the "raw" data and information do not exist without the context engendering knowledge. ${ }^{[6]}$ Robert Sternberg illustrated the relation between tacit knowledge and human's thinking and psychological process. He held that tacit knowledge is activityoriented and procedural, therefore its acquisition needs no help from others, and it encourages one to realize his personal life value. So the acquisition and application of such knowledge is vital to realistic life of human beings. ${ }^{[7]}$ And moreover, tacit knowledge reflects one person's capability of learning from practice and that of pursuing personal life objective, in which sense it would be tangible and countable. In one word, main methods for the acquisition and accumulation of tacit knowledge are different from that of explicit knowledge. Tacit knowledge can be generated through logical deduction and acquired through practical experience in the relevant context. In contrast, tacit knowledge can only be acquired through practical experience in the relevant context.

Thirdly, the transfer of tacit knowledge needs close interaction among different persons in a group. Since the process of transforming tacit knowledge into explicit or specifiable knowledge involves codification, articulation, or specification, so the tacit aspects of knowledge are those that cannot be codified, but can only be transmitted via training or gained through personal experience. Therefore the difficulty inherent within tacit knowledge transfer is that subject matter experts and key knowledge holders may not be aware, hence, unable to articulate, communicate and describe what they know. Therefore the distribution and effective use of tacit knowledge cannot be easily achieved through formal, systematic training. Instead, tacit knowledge needs direct, face-to-face contact. 
Actually, a lot of industry enterprises often use experiential learning techniques to train staff and to support them in learning from experiences, which includes unconscious learning, action learning and prospective learning.

And moreover, similar to the distinction of tacit knowledge from explicit knowledge, tacit knowledge could also be inspected from different view-angles. One is individual's life stage. In one's process of growing up, learning tacit knowledge occupies most of the time in childhood, and so even in adulthood stage. Second is field. Some fields' skills and knowledge are mostly of tacit, so that tacit knowledge is highly dependent on fields and professions, because the objective of learning knowledge is to solve realistic problems in practice. In another word, tacit knowledge determines the fate of that profession in some sense. ${ }^{[8]}$ Third, tacit knowledge has different patterns of storage and expression. As one person's direct experience implies tacit knowledge, while the social environment, cultural tradition and enterprise organization contain tacit knowledge, the relation between both is connected to individual's social dimension. Finally, if we take the historiography into consideration, we may find various characteristics of tacit in carrier, function, content and expression style and so forth.

Though the transform of knowledge happens in two directions, i.e. from explicit knowledge to tacit knowledge and vice verse, people primarily concern about the explicating of tacit knowledge. Among the models about transform mechanism, SECI proposed by Ikujiro Nonaka and Hirotaka is most well-known. They insist the creation of knowledge is a continuous process of dynamic interactions between tacit and explicit knowledge, in which four modes of conversion interact in the spiral that may trigger new spirals and becomes bigger as it moves upwards in an organization's hierarchy. The famous four modes are "Socialization", in which tacit knowledge is shared through face-to-face communication or experience such as apprenticeship; "Externalization", which is the key stage because concepts and knowledge structures are formed during it, "Combination", in which various elements of explicit knowledge move from one status to another, becoming into a more order structure, and finally "Internalization" links closely to learning by doing, because one has to transform the explicit knowledge into her knowledge base or thinking pattern in practice. They believe valuable tacit knowledge in an organization can be converted to explicit knowledge that is easy to distribute. Actually ISO9000 is based on the converting procedure of tacit knowledge explicating. As to sharing tacit knowledge, Harriet Zuckerman's statistic data of Nobel laureates shows us the role and effect of apprenticeship in the research works of top scientists, even in scientific research, face-to-face communication is illustrated to be the best way for a scientist to pursue Nobel Prize. ${ }^{[9]}$ Brain storm in term works is widely used in business organizations to enforce tacit knowledge communication.

VR (Virtual Reality) has caught imagination of people in all walks of life including teachers, whereas its value for education depends on human interface technology and recent achievements in cognitive theory, which is relevant to human learning. Because a person's psychological process is same no matter in VR or in reality when she constructs knowledge through interaction with objects. Immersion in a virtual world effectively removes the interface allowing us to cross the subject-object boundary that exists between us and the machine. ${ }^{[10]}$ One's experience in VR may be of almost exactly the same quality as that in the real world. That is why the tacit knowledge engendered could be simulated, including their direct, subjective and personal features. And the rapid development of information technology greatly facilitates the storage and reduplication of such tacit knowledge by VR.

If the objective of $\mathrm{KM}$ is to find new approaches for enterprises to realize sharing of tacit and explicit knowledge in order to achieve business interest, then the primary task of tacit $\mathrm{KM}$ would be creating a mechanism or platform to facilitate the inter-converting of both, because either type knowledge has its own role and functions in the historical practice of the human being. Once society, history and practice are involved to KM, investigation of their intrinsic qualities in the viewpoint of philosophy would be a certainly available approach for us to understand KM of both tacit and explicit type.

\section{PHILOSOPHICAL ANALYSIS OF TACIT KM}

By proposing the concept of tacit knowledge, Polanyi expands the limitation of knowledge. Knowledge is no longer isolated, independent, static and passive. On the contrary, it is inextricably bound to human, to human's life and practice, even human body according to phenomenology, so it is dynamic and developing. Various inquiries of tacit knowledge exploit a new prospect for the development of epistemology. However, Polanyi's theory does not tell the development of tacit knowledge in one person's life; neither does it elaborate different types of tacit knowledge by professions and fields, its relation to culture and history. Moreover, its relation to education remains a big space waiting for us to exploit. But all those respects are based on its philosophical analysis.

Knowledge is an ancient conception in the history of western philosophy. Plato elaborated that important concept, In Theaetetus. He attacked the idea that knowledge is identical to perception because a perception has no semantic structure so that we cannot state it. And he also refused the suggestion that knowledge is true belief since a belief is a semanticallystructured concatenation of sensory impressions. Even when someone is capable not only of using logical constructions in thought, but also of understanding how they arise from perception, that is still not knowledge either. Anyway, according to Plato, knowledge is indefinable in empiricist terms because they have no logos. However, that does not mean we can tell nothing about what knowledge is or is like. ${ }^{[11]}$ Since the 16 century, a lot of great philosophers including Descartes, Bacon, Locke, Hume and Kant have made brilliant achievements in knowledge and epistemology. In some sense, Kant successfully ended an age of speculation on knowledge typically expressed in David Hume's works, by bringing reason together with experience, though finally he fell into the hedge of traditional dualism philosophy.

Investigations upon tacit knowledge reveal its preemption in epistemology. All types of knowledge are based on tacit knowledge or are tacit themselves more or less, so a pure explicit knowledge is unimaginable as Polanyi said. ${ }^{[12]}$ Though we are always apt to describe knowledge in symbols explicitly, we may regard that as our scientific-likely method to 
understand, to grasp and put tacit knowledge to use. Without the tacit coefficients, all explicit knowledge in form of words, formula or propositions are inscrutable. In another word, tacit knowledge is the semantic foundation of explicit knowledge, because it is directly related to our activities, practice and intuition. That is determined by the complexity of the structure and process of our consciousness and cognition. According to Freud's psychoanalysis theory, subconsciousness primarily forms during one's childhood whereas has lifetime-long significant influence on the acts of human beings. In some sense, the relation between subconsciousness and consciousness resembles that of unreason and reason. The role of subconsciousness to our consciousness and intelligence is similar to that of tacit knowledge to explicit knowledge, and former could be understood as the ontological foundation of the latter. However, the essentiality of such unreason terms as intuition, will and emotion has been ignored by generations of philosophers in the history until the 20 century.

Jean Piajet's genetic epistemology not only affects Polanyi's idea on the progress of children's mind growing up, but inspires Nonaka's SECI model. Genetic epistemology clearly explains the process of how a human being develops cognitively from birth throughout her life through four primary stages of development, and the interaction between one stage to another is generalized as 2 modes of development, assimilation and accommodation, the former occurs when the learner could understand a new event or object in an existing schema, while the latter means one manage to hold a new experience according to the outcome of the tasks. And equilibration encompasses both assimilation and accommodation as the learner manages to arrive at a correct or different solution, which likely triggers an upper level of development. In addition to Piajet's influence, Gestalt psychology's emphasis on Holism of experience and activities is one theoretical resource of Polanyi, because he describes the basic structure of tacit knowledge as such a process of understanding that integrates all discrete parts into one. ${ }^{[13]}$ In addition, the "From-to" dynamic structure of tacit knowledge reveals its content in functional, phenomenal, semantic and ontological respects.

From the angle of viewpoint of management science, tacit $\mathrm{KM}$ promotes the level of management up to a so-called stage of "cultural management". The scope of this kind of cultural model covers more than the traditional management, in addition to the economic and organizational issues, it pays more attention on team building, efficiency improvement by the way of cultural construction, due to the cultural proficiency to human happiness, to the harmony of the organization and society, because knowledge, capabilities of people, value-views are all resources in addition to material and capital. Management is no longer only that kind of arrangement of dead materials, but more about life resources, implicit and soft resources such as tacit knowledge, structure and deployment of resources in an organization, in which knowledge, human's knowledge, trust environment building are essential elements. As the third KM suggests, all respects of KM will point to the construction of human community of practice.

Social ecology of knowledge management proposed by David Snowden is an efficient approach for philosophical analysis of KM. According to him, multi-disciplinary knowledge in areas such as brain science, neural network research, linguistics and cognitive theory may be used for reference to analyze the process of knowledge creation and conversion. This systemic model integrates knowledge, cognitive activities, human, and enterprise procedures under individual epistemology. It tries to explain activities of $\mathrm{KM}$ from philosophical angel of viewpoint, and has made some progress. Moreover, ecology of knowledge reveals such a fact: not all explicating of tacit knowledge are helpful, implicating, the contrary process, is also a necessary procedure in knowledge's life-time, they both are indispensable and complementary for a ecological system of knowledge. Actually, with the rapid change of the world, investigation on tacit knowledge is not limited within the field of knowledge theory or epistemology, but involves a lot of other disciplines such as philosophy of science, linguistic philosophy, hermeneutic, psychology, ethics and political philosophy and so forth.

In summary, tacit knowledge is a kind of action-inherent knowledge or action-constructive knowledge. It contains a lot of active elements' participation in the acquisition and transfer process of knowledge, so it displays a kind of philosophical value after the practical turn in modern philosophy, particularly in Marxism, phenomenology and Deweyan theory of experience. If we consult the recent philosophical development to assist analysis of tacit knowledge management, knowledge ecology is absolutely non-negligible due to its dynamic viewpoint.

\section{REFERENCES}

[1] Peter Drucker, Collected Works of Drucker[C] . Beijing: Mechanical Industry Press, 1999.45.

[2] Michael Polanyi: The Tacit Dimension[M], Chicago: The University of Chicago Press, 1966.4.

[3] Yogesh Malhotra, "Deciphering the Knowledge Management Hype," The Journal for Quality \& Participation, 1998(7/8).

[4] Michael Polanyi: The Study of Man[M], Chicago: The University of Chicago Press, 1958.12.

[5] Lam, A. Tacit Knowledge, Organizational Learning and Societal Institutions: An Integrated Framework. Organization Studies 21(3), 2000.487-513.

[6] Irit Alony, Greg Whymark, Michael Jones, Sharing Tacit Knowledge: A case study in the Australian Film Industry, Informing Science Journal, 2007(10).

[7] Robert J. Sternberg et al.. Practical Intelligence in Everyday Life [M].New York: Cambridge University Press, 2000.

[8] Sternberg R.J. \& Horvath, J.A., ed. al.; Tacit Knowledge in Professional Practice; Researcher and Perspectives, London; Lawrence Erlbaum Associates Inc. 1999.233.

[9] Harriet Zuckerman, Scientific Elite: Nobel Laureates in the United States, New York, The Free Pres, 1977.

[10] W. Bricken, Extended abstract: A formal foundation for cyberspace. In S.K. Helsel (Ed.), Beyond the vision: The technology, research and business of virtual reality. (Proceedings of the second annual conference of virtual reality, artificial reality and cyberspace, San Francisco, September.) Westport: Meckler. 1991.

[11] Plato, "Theaetetus", 148e, in Plato: The Collected Dialogues, New Jersey: Princeton University Press, 1961.853.

[12] Michael Polanyi. Knowing and Being[M], The University of Chicago Press, Chicago, 1969.144.

[13] Michael Polanyi, Tacit Dimension[M], Peter Smith, 1983.6. 